\title{
CHARACTERIZATION OF A CDNA CLONE FOR BARLEY LEAF GLUTAMINE SYNTHETASE
}

\author{
by \\ SIMONA BAIMA ${ }^{(2)}$, ANITA HAEGI ${ }^{1)}$, PER STRØMAN ${ }^{2)}$ \\ and GIORGIO CASADORO ${ }^{1.2 .3)}$ \\ 1)Dipartimento di Biologia, II Università di Roma, Italy \\ ${ }^{2}$ Department of Physiology, Carlsberg Laboratory, \\ Gamle Carlsberg Vej 10, DK-2500 Copenhagen Valby \\ ${ }^{3)}$ To whom correspondence should be addressed \\ Present address: Università di Padova, Dipartimento di Biologia, \\ Via Trieste 75, I-35121 Padova, Italy
}

Keywords: Chloroplastic glutamine synthetase, amino acid sequence homology, mRNA, dark grown seedlings, greening seedlings

\begin{abstract}
A barley cDNA clone (1182 bp) encoding chloroplastic glutamine synthetase was isolated with a heterologous cDNA probe of the gene specifying the enzyme from alfalfa. The clone, named pGS8, was found in a $\lambda_{g t} 11 \mathrm{cDNA}$ library prepared from dark grown barley leaves even though the chloroplastic glutamine synthetase is absent from such leaves. In agreement therewith the clone hybridized in Northern blot analyses with a $1.7 \mathrm{~kb}$ mRNA species present the in poly $\mathrm{A}^{*} \mathrm{mRNA}$ fraction of both dark grown and greened primary leaves of barley.

The nucleotide sequence of the barley clone reveals $75 \%$ identity to the Phaseolus vulgaris and Pisum sativum clones encoding chloroplastic glutamine synthetase, while only $69 \%$ identity is observed in comparisons with the clones specifying the cytosolic isozymes. At the amino acid level $85 \%$ identity is found between the deduced barley glutamine synthetase sequence and that of the corresponding chloroplastic isoenzymes from bean and pea. The chloroplastic glutamine synthetases contain conserved cysteins in the putative ATP and substrate binding sites. In the cytosolic forms these positions are occupied by alanine residues.
\end{abstract}

\section{INTRODUCTION}

In the nitrogen metabolism of higher plants, glutamine synthetase (EC 6.3.1.2) effects the primary assimilation of ammonia produced by nitrate reduction, by amino acid catabolism and by photorespiration. In 1979 MANN et al. (13), working with barley, discovered the presence of two glutamine synthetase isoenzymes in the leaves. The two isoforms, named glutamine synthetases 1 and 2, were found in different compartments of the cell, glutamine synthetase 1 being in the cytosol and glutamine synthetase 2 in the chloroplast. Testing both etiolated and illuminated barley seedlings, MANN et al. (13)

Abbreviations: $\mathrm{bp}=$ basepairs; $\mathrm{kb}=$ kilobasepairs; $\mathrm{kDa}=$ kilodalton; $\mathrm{SDS}=$ sodium dodecyl sulphate. 
also found that no glutamine synthetase 2 activity could be detected in dark grown plants.

Subsequently, many papers reported the presence of two glutamine synthetase isoforms in higher plant leaves. Clones encoding glutamine synthetase 1 and clones specifying glutamine synthetase 2 have recently been obtained and characterized $(6,10,21,22,23,24)$.

So far, no amino acid sequence for a monocotyledonous glutamine synthetase has been reported. The present paper presents the isolation and characterization of a cDNA fragment containing the coding region for the mature form of a barley glutamine synthetase.

\section{MATERIALS AND METHODS}

\subsection{Plant material}

Kernels of barley (Hordeum vulgare L.) were germinated in water-moistened vermiculite in the dark. Six-day-old seedlings were used for RNA extraction. Some plantlets were sampled without further treatment (etiolated) whereas other plantlets were illuminated for $12 \mathrm{~h}$ before the actual sampling (green).

\subsection{RNA isolation and Northern blot analysis}

Total RNA was extracted from barley leaves, both from etiolated (dark RNA) and green (light RNA) seedlings, using extraction by the guanidinium chloride method (11). Poly $\mathrm{A}^{+}$enriched RNA was isolated by Hybond ${ }^{\mathrm{TM}}$-mAP (Amersham) according to the manufacturer's specifications. For Northern blot analysis RNA was denatured at $60{ }^{\circ} \mathrm{C}$ for $10 \mathrm{~min}$ in gel running buffer $(0.04 \mathrm{M}$ morpholinopropane sulfonic acid pH 7.0, 10 mm sodium acetate, 1 mM EDTA pH 8.0) with formamide and formaldehyde (12), electrophoretically separated in either $1.2 \%$ or $1.4 \%$ agarose gels containing formaldehyde and transferred to nylon filters (Amersham). Filters were hybridized at $42{ }^{\circ} \mathrm{C}$ for $36 \mathrm{~h}$ in $50 \%$ formamide, $1 \mathrm{x}$ Denhardt's solution $(0.2 \mathrm{~g} / \mathrm{l}$ each of Ficoll, polyvinylpyrrolidone 4000 and bovine serum albumin), $5 x \mathrm{SSC}(0.75 \mathrm{M} \mathrm{NaCl}, 0.075 \mathrm{M}$ sodium citrate $\mathrm{pH} 7.0$ ), $20 \mathrm{mM} \mathrm{NaPO}_{4} \mathrm{pH} \mathrm{6.5}$, $10 \%$ dextran sulfate, $100 \mu \mathrm{g} / \mathrm{ml}$ denatured salmon sperm DNA, to a $1.2 \mathrm{~kb}$ alfalfa DNA probe labelled with $\alpha-{ }^{32} \mathrm{P}$ (specific activity $10^{8}$ $\mathrm{cpm} / \mu \mathrm{g}$ ). Filters were washed in $2 \mathrm{x}$ SSC, $0.1 \%$ SDS at room temperature, then $30^{\circ}$ in $0.1 \times$ SSC, $0.1 \%$ SDS at $42{ }^{\circ} \mathrm{C}$ (heterologous probe) or $60^{\prime}$ in $0.1 \times \mathrm{SSC}, 0.1 \%$ SDS at $48{ }^{\circ} \mathrm{C}$ (homologous probe), and exposed to $\mathrm{X}$-ray film at $-70^{\circ} \mathrm{C}$ with intensifying screen. The molecular weight markers were rRNAs according to PouLSEN (16).

\subsection{Plasmids, cDNA libraries and isolation of GS CDNA}

All our clonings were done in pLC18 plasmids (25). The plasmid pGS100, containing a $1.6 \mathrm{~kb}$ glutamine synthetase cDNA from alfalfa (3), was a gift from H.M. GoOdMan (Dept. of Molecular Biology and Dept. of Genetics, Harvard Medical School, Massachusetts, USA). The two $\lambda g t 11$ barley cDNA libraries, kindly donated by K. APEL (Botanisches Institut, ChristianAlbrechts Universität, Kiel, FRG), had been constructed from poly $\mathrm{A}^{+}$enriched RNA obtained from 5-day-old seedlings, grown, respectively, in complete darkness and in darkness followed by $18 \mathrm{~h}$ of light. The insert DNA was in the EcoRI site of the $\lambda \mathrm{gt} I \mathrm{l}$ vectors.

\subsection{DNA preparations}

Large scale plasmid DNA preparations were made using the alkaline lysis method (12) followed by equilibrium density gradient centrifugation with $\mathrm{CsCl}$ (12). Small scale plasmid DNA preparations were performed according to HATTORI and SAKAKI (7). Preparation of lambda DNA was done on a small scale according to KASLOW (8).

\subsection{Labelling of probes}

DNA fragments to be used as probes were cut out of the plasmids, electrophoresed on agarose gels, electroeluted and subsequently labelled with $a-\left[{ }^{32} \mathrm{P}\right]$-deoxynucleotides according to the random primed DNA labelling technique (5).

\subsection{Screening of the cDNA libraries}

The cDNA libraries were screened using the labelled $1.2 \mathrm{~kb} \mathrm{Bgl} \mathrm{II-Stu} \mathrm{I} \mathrm{fragment} \mathrm{of} \mathrm{the}$ pGS100 plasmid (3). Plaque lifts were made 
according to BENTON and DAVIS (1) and heterologous hybridization was performed at $60^{\circ} \mathrm{C}$ for $18 \mathrm{~h}$ in $10 \mathrm{x}$ Dentardt's solution, $4 \mathrm{x}$ TES $(0.6$ м NaCl, 8 mM EDTA, 120 mM Tris- $\mathrm{HCl} \mathrm{pH} \mathrm{8.0),}$ $0.1 \% \mathrm{SDS}, 100 \mu \mathrm{g} / \mathrm{ml}$ of denatured DNA and salmon sperm to the $\alpha-\left[{ }^{32} \mathrm{P}\right]$-labelled Bgl II-Stu I fragment from pGS100 (specific activity of $10^{8}$ $\mathrm{cpm} / \mu \mathrm{g}$ ). Filters were washed at $48^{\circ} \mathrm{C}$ for $90^{\prime}$ in $\mathrm{Ix}$ SSC and exposed to X-ray film with an intensifying screen at $-70^{\circ} \mathrm{C}$. The inserts of the positive clones were excised from lambda and subcloned into pUC18.

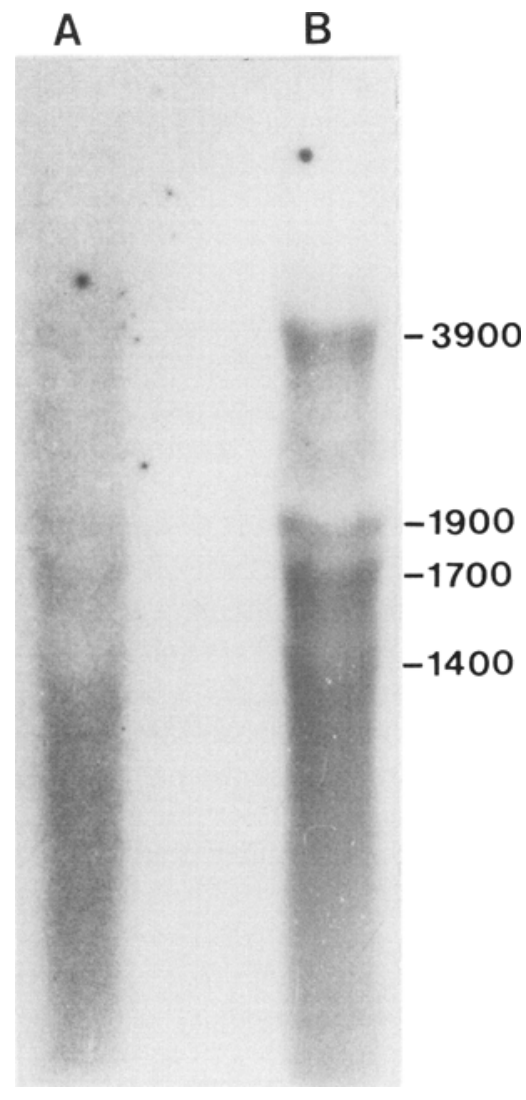

Figure 1. Northern analysis of RNA from etiolated (A) and green (B) barley leaves. $75 \mu \mathrm{g} /$ lane of total RNA were run in a $1.2 \%$ agarose/formaldehyde gel. The probe was the $1.2 \mathrm{~kb}$ Bgl II-Stu I fragment from alfalfa glutamine synthetase cDNA. RNA size is expressed in basepairs (bp). The 3900 and 1900 bp bands represent rRNA (16); the 1700 and 1400 bp bands constitute barley glutamine synthetase mRNAs.

\subsection{Nucleotide sequence analysis}

One of the positive clones, selected from the "dark" $\lambda$ gtl1 library, contained an insert of approximately $1200 \mathrm{bp}$ which was subcloned into pUC18 and the resulting plasmid named pGS8. The insert of pGS8 was sequenced by the dideoxy chain termination method with sequence of both strands determined for more than $55 \%$ of their lengths. The sequencing was done on double stranded plasmid DNA $(2,7)$ using chemically modified T7 DNA polymerase (20). We introduced a modification to the above method by using $3.5 \mu \mathrm{g} / \mu \mathrm{g}$ template DNA of E. coli single strand binding protein (19) in the labelling mix in order to overcome band compression in sequencing gels. Analysis of sequencing data was done with the Microgenie program developed by QUEEN and KORN (17).

\section{RESULTS}

Northern blot analysis was performed using total RNA, from both etiolated and green leaves, and a probe consisting of the $1.2 \mathrm{~kb} \mathrm{Bgl} \mathrm{II-Stu} \mathrm{I}$ fragment from the pGS 100 plasmid which contains a cDNA sequence coding for a cytosolic alfalfa glutamine synthetase (3). The result is shown in Figure 1, where 4 bands are visible in each lane. The two upper bands (3900 and 1900 bp) correspond to rRNA (16) whereas the 1700 and $1400 \mathrm{bp}$ bands represent the glutamine synthetase 2 and glutamine synthetase $1 \mathrm{mR}$ NA, respectively. Since our probe was heterologous we used a low stringency in this experiment; this might explain the fact that our probe (i.e. alfalfa GS1) can recognize both glutamine synthetase 1 and 2 mRNA.

By screening the $\lambda g t 11$ cDNA libraries, we were able to isolate 5 positive clones from the "dark" library and 7 from the "light" library, the latter containing only small sized inserts.

One of the "dark" clones (1200 bp) was chosen for further characterization. It was subcloned into pUC18 and named pGS8. On the basis of our Northern blot analysis and of the sizes of glutamine synthetase mRNAs from dicotyledonous plants, it was not expected to be of full-length. The insert of pGS8 was used, under high stringency conditions, as a probe in a Northern blot analysis with poly $\mathrm{A}^{+}$enriched 


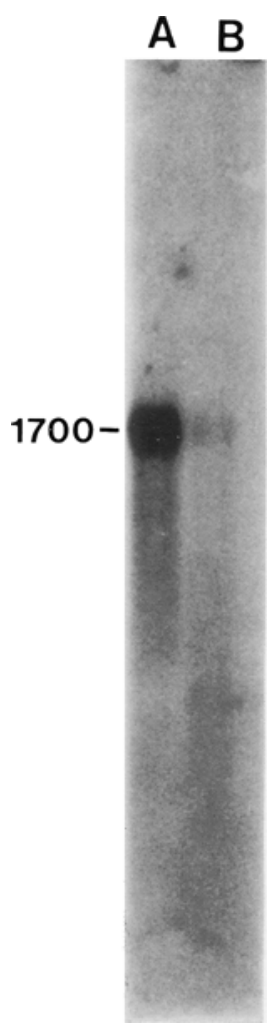

Figure 2. Northern analysis of poly $\mathrm{A}^{+}$enriched RNA from green (A) and etiolated (B) barley leaves. 15 $\mu \mathrm{g} /$ lane were fractionated by size in a $1.4 \%$ agarose/ formaldehyde gel. The probe was the EcoRI insert from pGS8. Molecular weights were calculated according to POULSF.N (16).

RNA from both light and dark grown barley leaves. A strong band of about $1.7 \mathrm{~kb}$ is visible in the lane of the "light" poly $\mathrm{A}^{+}$RNA, and a similar but fainter band is visible in the lane of the "dark" poly A+ RNA (Fig. 2).

In order to obtain fragments suitable for sequencing, the cloned insert of pGS8 was digested with different restriction enzymes and the selected fragments were re-cloned into pUC18. A restriction map of pGS8 along with the subclones and the sequencing strategy is shown in Figure 3.

Using both the direct and the reverse M13 universal primers it was possible to determine the complete sequence of both strands of the $\alpha$, $\beta$ and $\gamma$ Sau 3A fragments. The remaining sequence was obtained from the $\delta$ and $\varepsilon$ subclones and directly from sequencing the whole insert of pGS8.

The complete sequence of the pGS8 insert is $1182 \mathrm{bp}$ long and shown in Figure 4 together with the deduced amino acid sequence. Starting with the first base in the sequence the insert contains an open reading frame of $1161 \mathrm{bp}$ which codes for 387 amino acids and ends with an opal stop codon. This is followed by a second opal stop codon separated from the first by two amino acid codons and 9 bp of the $3^{\prime}$ non-coding region. The sequence has a $\mathrm{GC}$ content of $56.2 \%$ which is higher than the average $45.6 \%$ found in bariey genomic DNA (15).

The polypeptide deduced from the nucleotide sequence (Fig. 4) has a predicted molecular weight of about $42.5 \mathrm{kDa}$ and is dominatingly composed of acidic (12.66\% of Asp+Glu; $9.3 \%$ of Lys+Arg; estimated pI 5.76) and hydrophilic amino acids (only $26.6 \%$ of hydrophobic residues).

\section{DISCUSSION}

In 1979 ManN et al. (13) demonstrated that barley leaves contain two glutamine synthetase isoenzymes (GS1 and GS2) with molecular weights of 349 and $363 \mathrm{kDa}$, respectively. They also showed that no glutamine synthetase 2 activity could be detected in etiolated seedlings.

Our Northern blot analyses with both homologous (pGS8) and heterologous (pGS100) probes demonstrate that the presence of two barley glutamine synthetase isoforms is reflected by the presence of two different mRNAs $(1.4 \mathrm{~kb}$

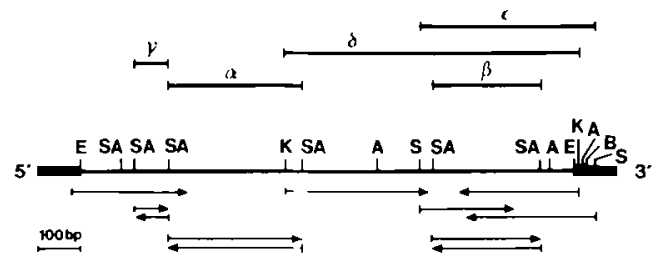

Figure 3. Restriction map and sequencing strategy for the $1.2 \mathrm{~kb}$ EcoRI - EcoRI fragment of pGS8. Arrows indicate the positions and directions of sequencing and the greek symbols mark individual DNA fragments subcloned in pUC18. E = EcoRI; SA = Sau 3A; K = KpnI; A = AvaI; B = BamHI; $\mathbf{S}=$ SphI. 
TCC GGG TIC AAG GTG CTG GCG CTC GGC COG GAG ACC ACC GCG GTC ATC CAG AGG ATG CAC

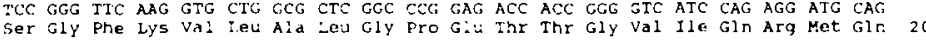

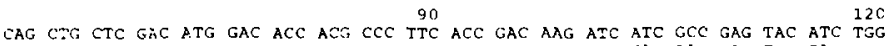
gla :ej leu Asp Met Asp thr thr pro pre thr Asp iys Ile Ile Ald Glu Tyr Ile trp 4 GTT GGA GGA ICT GGA ATT GAC CTC AGA AGC AAA TCA AGC ACG ATT TCC AAG CCA GTG GAC GTT GGA GGA ICT GGA ATT GAC CTC AGA AGC AAA TCA AGG ACG ATT TCC AAG CCA GTG GAG
Val Gly Gly Ser Gly Ile Asp :eu Arg Ser Lys Ser Arg thr Ile Ser Lys Pro Va: Glli 60 GAC CCG TCA GAG CTG CCG AAA TGG AAC TAC GAC GGA TCG AGC ACG GGG CAG GCT CCT GGG

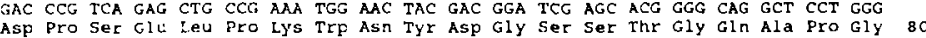
CAA

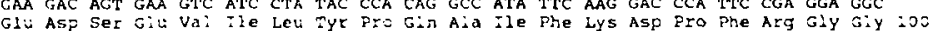
AAC AAC ATA CTG GTT ATC TGT GAC ACC 330 . 360 Asn Asn Ile Leu val Ile Cys Asp Thr Tyr Thr Pro Gln Gly Giu pro Ile Pro Thr Asn 120 AAA CGC CAC ATG GCT GCA CAA ATC TTC AGT GAC CCC AAG GTC ACT TCA CAA GTG CAA TGG Lys Arg His Met Ala Ala Gln Ile phe Ser Asp pro Lys Val thr Ser Gln val Gln trp 140

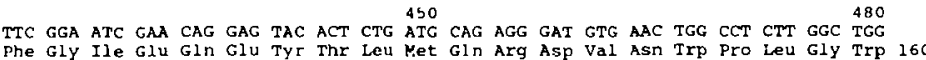
Phe GlY Ile Gau Gln Clu Tyr The Lou Met Gln $510 \quad 540$ CCT GTT GGA GGG TAC CCT GGC CCC CAG GGT CCA TAC TAC TGC GCC GTA GGA TCA GAC AAG
Pro Val Gly Gly Tyr pro Gly pro GIn Gly Pro Tyr Tyr Gys Ala Val Gly Ser Asp Lys 180 TCA Trit GGC 570 TCT GAC ATA TCA GAT 600 Ser phe Gly arg Asp Ile Ser Asp Ala His Tyr Iys Ala Cys Leu Tyr Ala Gly Ile Glu 200 630 COT GT 660 ATC AGT GGA ACA AAC GGG GAG GTC ATG CCT GGT CAG TGG GAG TAC CAC GTT GGA CCC AGC I le ser Gly Thr Asn Gly Glu val Met pro 690 GTT GGT ATT GAT GCA GGA GAC CAC ATA TGG GCT TCC AGA TAC ATT CTC GAG AGA ATC ACG val Giy lie Asp Ala Gly asp his Ile Trp Ala Ser Arg Tyr Ile Ieu Glu Arg Ile Thr 240 GAG CAA GCT GGT GTG GTG CTC ACC CTT GAC CCA AAA CCA ATC CAG GGT GAC TGG AAC GGA glu Gln Ala Gly Val Val Leu thr Leu Asp pro Lys pro Ile Gin Gly asp trp Asn Gly 260 GCT GGC TGC CAC ACA AaC TAC AGC ACA T10 Ala Gly Cys His thr Asn Tyr Ser Thr leu Ser Met Arg Glu Asp Gly Gly phe Asp val 280 ATC AAG AAG GCA ATC CTG AAC CTT TCA 870 CTT CGC CAT GAC TTG CAC ATK GCC GCA TAT GGT Ile lys Lys ala Ile Leu Asn teu Ser Leu Arg His Asp leu His Ile Ala Ala Tyr gly 300 GAA GGA AAC GAG CGG AGG TTG ACA GGG CTA CAC GAG ACA GCT AGC ATA ICA GAC TTC TCA Glu Gly Asn Glu Arg Arg Leu Thr Gly Leu His Glu Thr Ala ser Ile ser Asp phe Ser 320 TGG GGT GTG GCG AAC CGT GGC TGC TCT 990 ATT CGT GTG GGG CGA GAC ACC GAG GCG AAG GGC Trp Gly Val Ala Asn Arg Gly EYs Ser Ile Arg Val Gly Arg Asp Thr Glu Ala Lys Gly 340 AAA GGa TAC CTG GAG GAC CGT CGC CCG GCC TCC AAC ATG GAC CCG TAC ACC GTG ACG GCG Lys Gly Tyr Leu glu Asp Arg arg pro ala Ser Asn Met Asp pro tyr thr Val thr ala 360

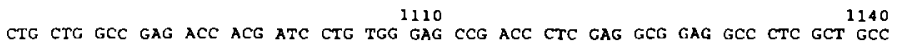
Leu Leu Ala Glu Thr thr Ile Leu Trp Glu Pro Thr leu Glu Ala Glu Ala leu Ala Ala 380 AAG AAG CTG GCG CTG AAG GTA TGA AGG 1170 TCC TGA AAA AAG GAC Lys liys Leu Ala Leu Lys vai End 


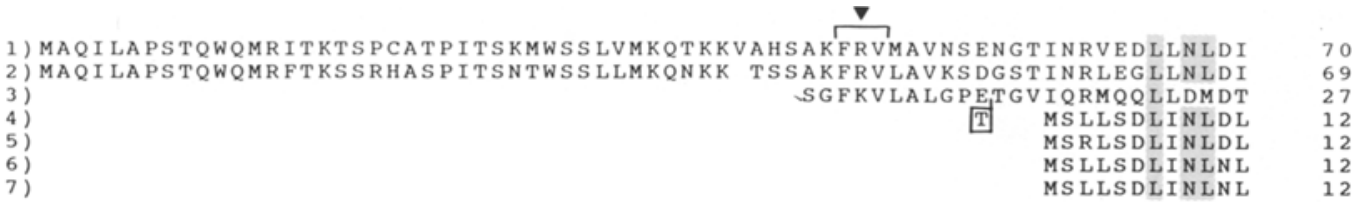

1) TPFTDSIIAEYIWIGGTGIDVRSKSRTISKPVSH SEVPKWNYDGSSTGQAPGEDSEVILYPQAIFKDPF 2) TPFTDKIIAEYIWIGGTGIDVRSKSRTISKPVEHPSELPKWNYDGSSTGQAPGEDSEVILYPQAIFKDPF 3) TPFTDKIIAEYIWVGGSGIDLRSKSRTISKPVEDPSELPKWNYDGSSTGQAPGEDSEVILYPQAIFKDPF 4 ) SETTEKI I AEY I W IGGSGLDLRSKARTLPG PVTDPSQLPKWNYDGSS'RGQAPGEDSEVIIYPQR IFKDPF 5) SGTTEKIIAEYIWIGGSGLDLRCKARTLPG PVTDPSELPKWNYDGSSTGQAPGQDSEVILYPQAIFKDPF 6) SDTTEKVIAEYIWIGGSG LDLRSKARTLPG PVKN PSELPKWNYDGSSTGQAPGQDSEVIIYPQAIFKDPF 7) SDSTEKI IAEYIWIGGSGMDLRSKARTLSGPVTDPAKLPKWNYDGSSTGQAPGEDSEVILYPQAIFKDPF

1) RGGNNILVVCDAYTPAGEPI PTNKRHRAAEIFSNPKVEAELPWYGIEOEYTLLOTNVKWPLGWPVGGYPG 2) RGGNNILVICDAYTPAGEPI PTNKRHRAAEVFSNPRVIAEVPWFGIEOEYTLLOTNVNWPLGWPVGGYPG 3) RGGNNILVICDTYTPQGEPI PTNKRHMA AQIFSDPKVTSQVPWFGIEQEYTLMQRDVNWPLGWPVGGYPG 4 ) RRGNNILVMCDAYTPAGEPI PTNKRHAAAKIFSHPDVVAEVPWYGIEQEYTLLQKDINWPLGWPVGGFPG

5) RRGNHILVMCDAYS PAGEPI PTNKRHAAAKVFSHPDVVAEETWYGIEQEYTLLQKDINWPLGWPAGGYPG

6) RRGNNILVICDAYT PAGEPI PTN KRHNAAKIFSN PDVVAEEPWYGI EQEYTLLOKEVNWPVGWPVGGFPG

7) RRGNNILVMCDAYTPAGEPI PTNKRHAAAKIFSNPDVVAEEPWYGIEQEYTLLQRDINWPLGWPIGGFPG$$
\text { * }
$$

1) PQGPYY CA AGA DKS FGRDISDAHYKACI YAGINISGTNGEVMPGQWEYQVGPSVGIEAGDHIWASRYILE 2) $P Q G P Y Y C S A G A D K S F G R D I S D A H Y K A C L F A G I N I S G T N G E V M P G Q W E Y Q V G P S V G I E A G D H I W A S R I L E$ 3) PQGPYY CAVGSDKS FGRDISDAHYKACLYAGIEISGTNGEVMPGQWEYQVGPSVGIDAGDHIWASRYILE 4) PQG PYY CGAGA DKA FGRDIVDSHY KA CLYAGINISGINGEVMPGQWEFQVGPSVGISAGDEIWVARYI LE 5) POG PYY CSVGADKAFGRDVVEAHYKACLFAGINISGINGEVMPGQWEFOVGPSVGISAGDEIWVARYILE 6) PQGPYYCGVGADKAFGRDIVDAHYKACVYAGINISGINGEVMPGQWEFQVGPAVGISAGDEL WVARYILE

\section{1}

1) RITEQAGVVLTLDPKPIEGDWNGAGCHTNYSTKSMREDGGFEVIKKAI LNLS LRHKIHIEAYGEGNERRI 2) RITEQAGVVLS LDPKPIEGDWNGAGCHTNYST KSMREDGGFEVIKKAILNLS LRHKEHISAYGEGNERRI 3) RITEQAGVVLTLDPKPIQGDWNGAGCHTNYSTLSMREDGGFDVIKKAILNLS LRHDLHIAAYGEGNERRL 4 ) RITEVAGVVLSFDPKPIKGDWNGAGAHTNYSTKSMREDGGYEVILKAIEKLGKKHKEHIAAYGEGNERRI 5) RITEVAGVVLTF DPKPIKGDWNGAGAHTNYSTKSMREDGGYEIIKKAIEKLGKRLPEHISAYGEGNERRI 6) RITEVAGVVLSFDPKPIKGDWNGAGAHTNYSTKTMRNDGGYEEIKSAIQKLGKRHKEHIAAYGEGNERRL

7) RIAEIAGVVVSFDPKPIPGDWNGAGAHTNYSTKSMREDGGYEVILKAIEKLGLKHKEHIAAYGEGNERRL

1) TGKHETAS INDFSWGVANRGCSIRVGRDTEKNGKGYLEDRRPASNMDPYVVTALLAESTLLWEPTLEAEA

2) TGKHETAS INTFSWGVANRGCSIRVGRDTEKNGKGYLEDRRPASNMDPYVVTSLLAESTLLWEPTLEAEA

3) TGLHETASIS DFSWGVANRGCSIRVGRDTEAKGKGYLEDRRPASNMDPYTVTALLAETTILWEPTLEAEA

4) TGRHETADINTF LWGVANRGAS IRVGRDTEKAGKGYFEDRRPSSNMDPYVVTSMIADTTILWKP

5) TGKHETADINTFSWGVANRGASVRVGRDTEKEGKGYFEDRRPASNMDPYVVTSMIAETTILLKP

6) TGRHETADINTFLWGVANRGASIRVGRDTEKAGKGYFEDRRPASNMDPYVVTSMIADTTILWKP

7) TGKHETAN ISTFKWGVANRGASVRVGRDTEKAGKGYFEDRRPASNMDPYVVTAMIADTTIIGKS

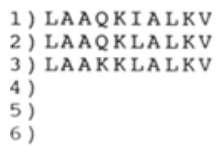

\author{
1) Pisum chloroplastic \\ 2) Phaseolus chloroplastic \\ 3) Hordeum chloroplastic \\ 4) Medicago cytosolic \\ 5) Pisum cytosolic \\ 6) Phaseolus cytosolic pR1 \\ 7) Nicotiana cytosolic
}

Figure 5. Comparison of the deduced primary structure of higher plant glutamine synthetases from pea (22, 23), bean $(6,10)$, barley, alfalfa (24) and tobacco (21). Asterisks indicate cysteins common to all glutamine synthetases; arrows indicate cysteins unique for chloroplastic glutamine synthetases. I and II mark regions highly conserved in both prokaryotic and eukaryotic glutamine synthetases (24). 
and $1.7 \mathrm{~kb}$ ). Hybridization under high stringency conditions of poly $\mathrm{A}^{+}$enriched RNA with the pGS8 probe from barley was exclusively with transcripts of $1.7 \mathrm{~kb}$, suggesting that the pGS8 insert corresponds to a cDNA coding for the higher molecular weight glutamine synthetase 2 located in the chloroplasts. This is substantiated by the closer similarity of the primary structure of this enzyme with the chloroplastic glutamine synthetase from pea and bean (Fig. 5) than with that of the cytosolic isoenzymes in these species.

The presence of a $1.7 \mathrm{~kb}$ transcript in the "dark" poly A" RNA and the fact that the pGS8 insert was actually isolated from the "dark" library reveals that some glutamine synthetase 2 mRNA must be present in etiolated leaves even though MANiv et al. (13) could not detect any glutamine synthetase 2 activity. The increase in the steady state level of the $1.7 \mathrm{~kb}$ mRNA upon illumination of etiolated leaves might reflect an increase in transcription and/or mRNA stability.

The deduced amino acid sequence of the open reading frame of clone pGS8 from barley has $85 \%$ identity with the chloroplastic glutamine synthetases of Phaseolus vulgaris and Pisum sativum, similarity at the nucleotide level being $75 \%$ and $74 \%$, respectively (Fig. 5). A corresponding comparison of pGS 8 with the deduced amino acid sequences for cytosolic glutamine synthetases of Phaseolus vulgaris, Pisum sativum, Medicago sativa and Nicotiana plumbaginifolia yields a lower degree of identity ranging from $74 \%$ to $76 \%$ and at the nucleotide level the similarity is only $69 \%$ to $70 \%$.

It is apparent from Figure 5 that the primary structures of chloroplastic and cytosolic glutamine synthetases of the dicotyledonous species have large conserved domains also present in the barley enzyme. The chloroplastic glutamine synthetases of pea and bean have an $\mathrm{N}$-terminal extension of 58 and 57 amino acids when aligned with their cytosolic counterparts. The deduced amino acid sequence for the barley glutamine synthetase has the extension beyond the amino terminal methionine of the mature cytosolic glutamine synthetases. It has been suggested that the $\mathrm{N}$-terminal extension of the leguminous chloroplastic glutamine synthetases constitutes the transit peptide for import into the chloroplast $(10,23)$ and that the cleavage site according to the consensus sequence of KARLINNELMANN and TOBIN (9) is located in the tripeptide FRV (cf. Fig. 5). The barley sequence extends beyond this point and contains at this position the tripeptide FKV. The replacement of the arginine residue with a lysine residue is considered as a conservative amino acid replacement. The barley clone misses the coding region for the major part of the putative transit peptide. If the FKV tripeptide indeed is the cleavage site the 16 amino terminal residues of the mature barley enzyme show little sequence similarity to the chloroplastic glutamine synthetase of pea and bean.

The mature chloroplastic glutamine synthetases are characterized by a 16 amino acid extension of the carboxyterminal end when aligned with the cytosolic isoenzymes (Fig. 5). Fifteen of the 16 amino acids of this carboxyterminal peptide are identical, while a glutamine in the leguminous enzyme is replaced by a lysine in the barley glutamine synthetase at position 7 upstream from the carboxyterminal valine.

According to EVSTIGNEEVA et al. (4) the binding of ammonia and ATP to glutamine synthetase involves cystein SH-groups. Complete inhibition of the enzyme occurred upon modification of two $\mathrm{SH}$-groups in the chloroplastic glutamine syntheidse monomer. In Lemna minor, which only has glutamine synthetase 2 activity (14), and in barley the chloroplastic glutamine synthetases are inactivated by thiol reactive agents, while the cytosolic isoenzyme is not affected by these treatments $(13,18)$. This specificity of thiol reagents may be related to the extra cystein residues consistently found in the chloroplastic enzyme (positions 263 and 328 in barley glutamine synthetase), whereas the four cytosolic enzymes studied contain an alanine residue in these two positions.

Comparisons of the amino acid sequences of eukaryotic and prokaryotic glutamine synthetases led TISCHER et al. (24) to suggest an ATP-binding domain which is marked $I$ in Figure 5. This domain shows faint similarities to the ATP-binding sites of other proteins. Domain II shows sequence relationships to the substrate binding site of bovine glutamate dehydrogenase and is therefore proposed as part of the substrate 
binding site of glutamine synthetase (24). It is interesting to note that the two additional cysteine residues of the chloroplastic glutamine synthetases are located within these two domains.

\section{ACKNOWLEDGEMENTS}

C. CASADORO is grateful to Professor H.M. Goodman (Dept. of Molecular Biology and Dept. of Genetics, Harvard Medical School, Massachusetts, USA) for the gift of the alfalfa GS probe, and to Professor K. APEL (Botanisches Institut, Christian-Albrechts Universitãt, Kiel, FRG) for the gift of the cDNA libraries. Professor DITER vON WETTSTEIN is thanked for his support and critical review of the manuscript. Drs. R. CaIzZI. A. BRANDT, V. SIMPSON, B. GRIMM are thanked for their support in the experimental work.

This research was financially supported by C.N.R.

\section{REFERENCES}

1. BENTON.W.D. \& R.W.DAVIS: Screening gt recombinant clones by hybridization to single plaques in situ. Science 196, 180-182 (1977)

2. Chen, E.Y.\& P.H. SeEblrg: Supercoil sequencing: A fast and simple method for sequencing plasmid DNA. DNA 4, 165-170 (1985)

3. DasSarma, S., E. Tischer \& H.M. Goodman: Plant glutamine synthetase complements a $g \ln A$ mutation in E. coli. Science 232, 1242-1244 (1986)

4. Evstigneeva,Z.G..A.V.Pushkin, N.P. Akentyeva \& W.L. KRETOviCH: Active site of glutamine synthetases from chloroplasts and cytosol of pea leaves. Physiol. Vég. 23, 861-868 (1985)

5. Feinberg, A.P. \& B. VoGelstirin: A technique for radiolabelling DNA restriction endonuclease fragments to high specific activity. Anal. Biochem. 137, 266-267 (1984)

6. Gebhardt, C. J.E. Oliver. B.G. Forde. R. SaAreLAINEN \& B.J. MIFLIN: Primary structure and differential expression of glutamine synthetase genes in nodules roots and leaves of Phaseolus vulgaris. EMBO J. 5, 1429-1435 (1986)

7. HATTORI, M. \& I. SAKAKI: Dideoxy sequencing method using denatured plasmid templates. Anal. Biochem. 152, 232-238 (1986)

8. KASLOW. D.C.: A rapid biochemical method for pyrifying lambda DNA from phage lysates. Nucleic Acids Res. 14. 6767 (1986)
9. Karlin-Neumann, G.A. \& E.M. Tobin: Transit peptides of nuclear-encoded chloroplast proteins share a common amino acid framework. EMBO J. 5, 9-13 (1986)

10. Lightfoot, D.A., N.K Green \& J.V. Cullimore: The chloroplast-located glutamine synthetase of Phaseolus vulgaris L.: nucleotide sequence, expression in different organs and uptake into isolated chloroplasts. Plant Mol. Biol. 11, 191-202 (1988)

11. Logemanv, J., J. SChfll \& L. Willmitzer: Improved method for the isolation of RNA from plant tissue. Anal. Biochem. 163, 16-20 (1987)

12. Maniatis, T., E.F. Fritsch \& J. Sambrook: Molecular cloning. A laboratory manual. Cold Spring Harbor Laboratory, New York (1982)

13. MANN. A.F..P.A. FENTEM \& G.R.STEWART: Identification of two forms of glutamine synthetase in barley (Hordeum vulgare). Biochem. Biophys. Res. Commun. 88, 515-521 (1979)

14. MCNaI.LY, S.F., B. HiRel, P. Gadal, A.F. MaNN \& G.R. STEWART: Glutamine synthetase isoforms in higher plants. Evidence for a specific isoform content related to their possible physiological role and their compartmentation within the leaf. Plant Physiol. 72, 22-25 (1983)

15. Mei.zer. J.M. \& A. KLeinhofs: Molecular genetics of barley. Barley Genetics V, 481-491 (1987)

16. POLLSEN, C.: The barley chloroplast genome: physical structure and transcriptional activity in vivo. Carlsberg Res. Commun. 48, 57-80 (1983)

17. QUEEN,C.\&L.J.KORN: A comprehensive sequence analysis program for the IBM personal computer. Nucleic Acids Res. 12, 581-599 (1984)

18. Rhodes, D., A.P. Sims \& G.R. STEWART: Glutamine synthetase and the control of nitrogen assimilation in Lemna minor. In: Nitrogen Assimilation in Plants. E.J. Hewitt \& C. V. Cutting Eds., Academic Press, NY, London, 501-520 (1979)

19. Sigalm N., H. Del.ius, T. Kornberg, M. Gefter \& B. AlBerTS: A DNA unwinding protein isolated from $E$. coli. Its interactions with DNA and with DNA polymerases. Proc. Natl. Acad. Sci. USA 69, 3537-3541 (1972)

20. TABOR, S. \& C.C. RICHARDSON: DNA sequence analysis with a modified bacteriophage T7 DNA polymerase. Proc. Natl. Acad. Sci. USA 84, 4767 4771 (1987)

21. Tingey, S.V. \& G.M. Coruzzi: Glutamine synthetase of Nicotiana plumbaginifolia. Cloning and in vivo expression. Plant Physiol. 84, 366-373 (1987)

22. Tingey. S.V., E.L. Walker \& G.M. Coruzzi: Glutamine synthetase genes of pea encode distinct polypeptides which are differentially expressed in 
leaves, roots and nodules. EMBO J. 6, 1-9 (1987)

23. TINGEY, S.V., F.Y. TSAI, J.W. EDWARDS, E.L. WALKER \& G.M. CORUZZI: Chloroplast and cytosolic glutamine synthetase are encoded by homologous nuclear genes which are differentially expressed in vivo. J. Biol. Chem. 263, 9651-9657 (1988)

24. Tischer, E., S. DasSarma \& H.M. GoOdMan: Nucleotide sequence of an alfalfa glutamine synthetase gene. Mol. Gen. Genet. 203, 221-229 (1986)

Accepted by S.O. ANDERSEN
25. Yanisch-Perron, C., J. VieIRA \& J. Messing: Improved M13 phage cloning vectors and host strains: nucleotide sequences of the M13mp 18 and $\mathrm{pUC} 19$ vectors and host strains: nucleotide sequence of the M13mp18 and pUC19 vectors. Gene 33, 103-119 (1985) 